\title{
Vikram A Sarabhai Community Science Centre
}

\author{
Dilip Surkar* \\ Vikram A Sarabhai Community Science Centre, Ahmedabad 380 009, India
}

\section{Genesis}

Dr Sarabhai was concerned about the quality of science education in India and felt that it did not adequately provide familiarization with the scientific method or the acquisition of knowledge through experimentation. To address these challenges, he initiated the 'Group for Improvement of Science Education (GISE)' in Physical Research Laboratory, Ahmedabad. Activities of GISE took shape of the 'Community Science Centre' in 1966 as a facility where those concerned about the quality of science education could come together to experiment and try out new ideas and techniques for teaching science. After Sarabhai's death in 1971, the Centre was renamed as the 'Vikram A Sarabhai Community Science Centre' in his honour.

\section{Vision}

VASCSC aims to nurture young minds and direct them towards scientific thinking with methods and techniques which make the process of enquiry and learning a funfilled, enjoyable and lasting experience. It works to stimulate interest, encourage and expose the principles of science and the scientific method to students, develop the ability to solve problems and make clear the social implication of science and technology; thereby improving the quality of science education.

\section{Symbol}

VASCSC's symbol illustrates the mandate of spreading the joy of science to different groups. The five arrow-

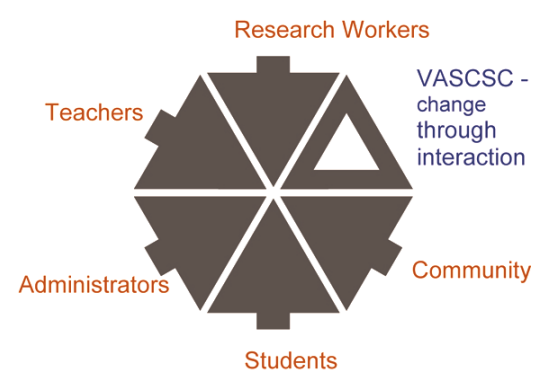

*e-mail: dilipsurkar@vascsc.org heads therein represent groups comprising teachers, students, researchers, administrators and the community, while VASCSC is represented by Delta - the mathematical symbol of change as it works to bring about change by providing a common platform to these groups.

\section{Facilities}

The Centre is open for all and has facilities like wellequipped laboratories in Biology, Chemistry, Computers, Electronics, Mathematics, Physics and Model Rocketry; Innovation Hub; Science Playground; Library; Workshop and Science Shop.

\section{Some firsts...}

VASCSC has pioneered concepts such as the first interactive exhibition space, open laboratories, mathematics laboratory, science playground, actively use computers in science education and develop interactive (animated) educational programmes based on Indian school science curriculum.

\section{Activities}

VASCSC's activities focus on experiential learning to create interest and develop understanding of science and mathematics among children. Consequently, they are motivated to pursue higher studies or research in pure science. Activities have been initiated to create spirit of innovation and making them future-ready through developing their skills in emerging technologies, critical thinking, design thinking and problem solving.

Capacity building of science educators is a major focus area. Teachers training workshops on 'Hands-on approaches in science and mathematics education' are conducted for professional development of teachers and to expose them to hands-on methodology for effective teaching-learning process.

Whether helping to instill scientific temperament or encouraging people to explore and innovate, VASCSC has been playing a significant role in developing a rational outlook by improving the basic understanding of science. 
Some major activities of the Centre include the popular Science Express (project of the Dept of Science and Technology, Govt of India). This exhibition train made 9 rounds across the country from 2007 to 2017, during which 18.2 million visitors were received. Also, VASCSC is furthering its reach to remote areas in Gujarat through the Mobile Science Lab which takes the lab experience to students right in their school. It has also helped develop programmes for Satellite Institutional Television Experiment (SITE) in 1971. The Teaching Learning Material developed by VASCSC is used by schools across India.

For its innovative work, the Centre has received several awards including the "National Award for Outstanding Efforts in Science and Technology Communication' from the Dept of Science and Technology, Govt of India (2008) and the 'Times of India Social Impact Award' for Education (2011).

\section{Guidance}

Dr Sarabhai not only provided leadership in Centre's development, but also took an active interest in implementation of various programmes, setting up of its facilities including the design and construction of the building. He visited the Centre regularly and interacted with participants and team.

Many distinguished scientists and personalities have been directly associated with the Centre in different contexts. These include Prof. C. V. Raman, Dr A. P. J. Abdul Kalam, Prof. M. G. K. Menon, Prof. M. S. Swaminathan, Prof. P. C. Vaidya, Dr Yash Pal, Shri Krishna Kripalani, Prof. A. R. Rao, Dr Madhav Gadgil, Dr. P. R. Pisharoty, Dr K. S. Karnik, Dr K. R. Ramanathan, Smt Vijaya Mulay, Shri V. G. Kulkarni, and others. Prof. K. Kasturirangan currently chairs the VASCSC Board of Governors.

doi: $10.18520 / \mathrm{cs} / \mathrm{v} 118 / \mathrm{i} 8 / 1213-1214$ 